\title{
Sea ice drift in the Arctic since the 1950s
}

\author{
Sirpa Hakkinen, ${ }^{1}$ Andrey Proshutinsky, ${ }^{2}$ and Igor Ashik ${ }^{3}$ \\ Received 25 May 2008; revised 8 August 2008; accepted 26 August 2008; published 3 October 2008.
}

[1] Sea ice drift data (from Russian North Pole stations, various ice camps, and the International Arctic Buoy Program) and surface wind stress data from the NCAR/ NCEP Reanalysis are analyzed to determine their long-term trends and causality. The study finds that both parameters (ice drift and wind stress) show gradual acceleration over last 50 years. Significant positive trends are present in both winter and summer data. The major cause of observed positive trends is increasing Arctic storm activity over the Transpolar Drift Stream caused by a shift of storm tracks toward higher latitudes. It is speculated, with some observational evidence, that the increased stirring of the ocean by winds could hasten the transition of the Arctic toward a weakly stratified ocean with a potential for deep convection and a new sink for atmospheric $\mathrm{CO}_{2}$. Citation: Hakkinen, S., A. Proshutinsky, and I. Ashik (2008), Sea ice drift in the Arctic since the 1950s, Geophys. Res. Lett., 35, L19704, doi:10.1029/2008GL034791.

\section{Introduction}

[2] The last decade has been characterized by a nearly monotonic decrease in summer Arctic ice extent, accompanied by a diminishing multi-year ice component [Comiso, 2002, 2006; Nghiem et al., 2007; Stroeve et al., 2007]. Some of the recent decrease in summer ice extent is related to increased export of sea ice from the Arctic by the enhanced Transpolar Drift Stream (TDS) [Nghiem et al., 2007]. Another recent example of rapid ice movement in TDS occurred when the schooner Tara was frozen into the Arctic drifting ice in September 2006 to emulate the 18941896 drift of Fram - instead, Tara exited the Arctic basin twice as fast as Fram [Gascard et al., 2008].

[3] Nghiem et al. [2007] analyzed sea ice drift based on buoy observations and linked observed pulses in increased drift speed to changes in wind speed (from the NCEP/ NCAR Reanalysis). This is not particularly surprising as sea ice drift responds within a few hours to atmospheric wind forcing. Thus, sea ice drift provides an excellent test bed for ideas about whether storm frequency and/or intensity has increased in the Arctic in the warming climate. Koenig et al. [1993] suggest that global warming is associated with increased cyclone frequency at high latitudes. Serreze et al. [1997] traced storm tracks (north of $60^{\circ} \mathrm{N}$ ) toward the Arctic and noted increasing cold-season storm tracks between 1966/1967 and 1992/1993 associated with a decrease in the tracks in the latitude band $30^{\circ} \mathrm{N}-60^{\circ} \mathrm{N}$. McCabe et al. [2001] repeated their study with the longer time series from

\footnotetext{
${ }^{1}$ NASA Goddard Space Flight Center, Greenbelt, Maryland, USA. USA.

${ }^{2}$ Woods Hole Oceanographic Institution, Woods Hole, Massachusetts,

${ }^{3}$ Arctic and Antarctic Research Institute, St. Petersburg, Russia.
}

the NCEP/NCAR Reanalysis (1959-1997) and found a similar increase in high-latitude storms and a decrease at mid-latitudes. They also determined that the intensity of the storms increased at mid and high latitudes. Serreze and Barrett [2008] reanalyzed summer season cyclone activity and found no increase in it. This is in contrast to Zhang et al. [2004], who find increased storm count and intensity in the Arctic, especially in the summer season during 19482002. Sorteberg and Walsh [2008] also find increasing trends in all seasons except winter. The spatial variability of the central Arctic versus coastal areas may also be critical as Atkinson [2005] finds low-frequency variability in storm activity in the circum-Arctic coastal regime, but no sustained trends over the period 1950-2000. Manson and Solomon [2007] analyzed wind speeds off the Northwest Territories from station data records (1958-2000) and from the Canadian Coupled Climate Model scenarios to predict coastal impact. Their observational record at that location did not show clear trends for past changes, but a coupledmodel future scenario exhibits increased storm frequency and intensity during the winter season.

[4] The above referenced analyses are not in agreement about sustained trends in storm activity, but most of them suggest increased storm activity in the high Arctic over the last 50 years, a time when Arctic air temperatures have risen considerably. $\mathrm{CO}_{2}$ scenarios in coupled climate models, for example, the IPCC $\mathrm{CO}_{2}$ (SRES A1B) scenario simulation with the ECHAM5 model, suggest that the Arctic iceocean system would not be impacted by more storms, with the exception of increased summer-storm intensity [Bengtsson et al., 2006]. Our goal is to provide an independent measure of whether increased storminess has a detectable impact on ice drift. Increased storm frequency and/or intensity can create more intense mixing beneath the sea ice cover by direct stirring and also by creating open water for ice formation and salt rejection. Both of these processes can adversely affect the halocline by potentially leading to its erosion and heat release from the ocean, at least in limited areas.

\section{Data}

[5] The ice drift data for this study was retrieved mainly from the National Ice and Snow Data Center (NSIDC). Although the earliest short drift records date to end of the 19th century (the Austrian ship Tegethoff and Nansen's Fram), our focus is to more closely investigate ice drift variability from 1950 to 2006 . The more "modern" records are available from Soviet North Pole stations (1937, 1950, and 1954-1970). Data from NP stations $1-2,4$, and 6-20 are available from NSIDC, and the information for stations 3 , 5, and 21-31 is available from the Arctic and Antarctic Research Institute archives. We also analyzed data from International Geophysical Year ice camps (1957-1959), T-3 (Fletcher Ice Island, 1959-1970), ARLIS-II ice camp 

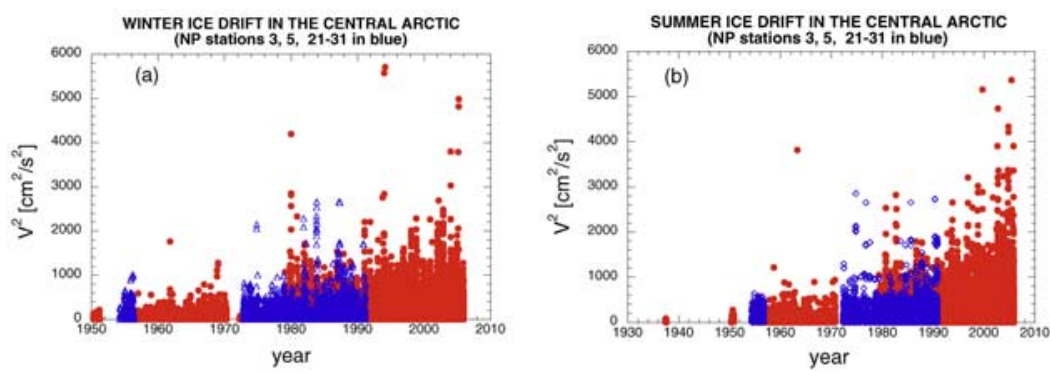

Figure 1. Ice drift observations (in terms of speed squared) sorted into (a) winter and (b) summer values. Red circles denote National Ice and Snow Center data, and blue squares Arctic and Antarctic Research Institute data.

(1961-1965), British Transarctic Expedition (1968-1969), and AIDJEX buoys [1972]. A more continuous record (every 12 hours) of buoy tracks is available from the International Arctic Buoy Program (IABP) since 1979. The NSIDC data records report the drift speed for the early stations. The IABP buoy drift is reported as time and coordinates with a sampling interval of 12 hours. We calculated drift speeds for IABP buoy data as a distance on a sphere between two buoy positions divided by the time interval, usually 12 hours, but, in case of missing data, not longer than 2 days.

[6] Since day-to-day fluctuations of sea ice drift are mainly driven by the atmosphere (and tides, but tides do not contribute to long term changes), we take a simple approach to investigate wind stress changes from the NCEP/ NCAR Reanalysis project data for 1948-2006. The monthly wind stresses were derived from data taken every 6 hours, thus preserving storm effects (since wind stress is a squared product of wind components) of originating from both changes in storm count and in storm intensity. Unlike in the sea level pressure (SLP) analysis used for storm activity by authors referenced in the introduction, we do not isolate the effects of storm count and storm intensity when using the monthly wind stress magnitude.

\section{Analysis of Sea Ice Motion From Drifting Stations and Buoys}

[7] As the first step, we simply compiled all available drift speeds into a time series for winter (November through

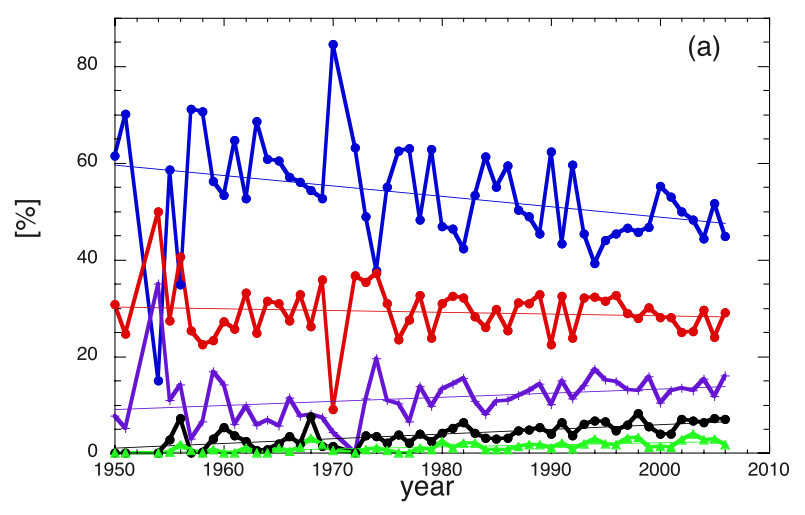

April) and summer (May through October). To concentrate on the central basin drift and capture changes in TDS, we selected drift data from buoy tracks within 10 degrees (on a great circle) of a central point located at $196^{\circ} \mathrm{E}, 83^{\circ} \mathrm{N}$ (not shown; it covers all deep basins excluding only Siberian and Alaskan coastal regions). The choice of region can bias the IABP toward slower speeds as it extends toward the Canadian Archipelago, but it should include the fastest buoys in the TDS.

[8] Figure 1 shows the result of this compilation. The increasing maximum drift values lead to an apparent conclusion that sea ice drift has accelerated over time, assuming that the early observations were representative of sea ice drift and qualitatively on par with IABP 12 hourly observations. The envelope of summer ice drift increases more steeply than that of the winter drift due to increased open water, less resistance from internal friction and probably due to ice thickness reduction relative to previous decades. Interestingly, the increased storm activity in the early 1990s accompanied by anomalous positive indexes of North Atlantic and Arctic Oscillation (NAO and AO) [Zhang et al., 2004] appears in Figure 1a as a localized peak in the winter ice drift. However, it is dwarfed by the subsequent increase in the ice drift speeds in the 2000s.

[9] To obtain another view that could be statistically tested, we divided the ice drift into speed categories designating 10 categories stepping from $5 \mathrm{~cm} / \mathrm{s}$ to $50 \mathrm{~cm} / \mathrm{s}$ and an $11^{\text {th }}$ step for speeds over $50 \mathrm{~cm} / \mathrm{s}$. Only the $0 \mathrm{Z}$ and $12 \mathrm{Z}$ observations were used. First, we show the percentage of speeds in each category in summer and winter to indicate

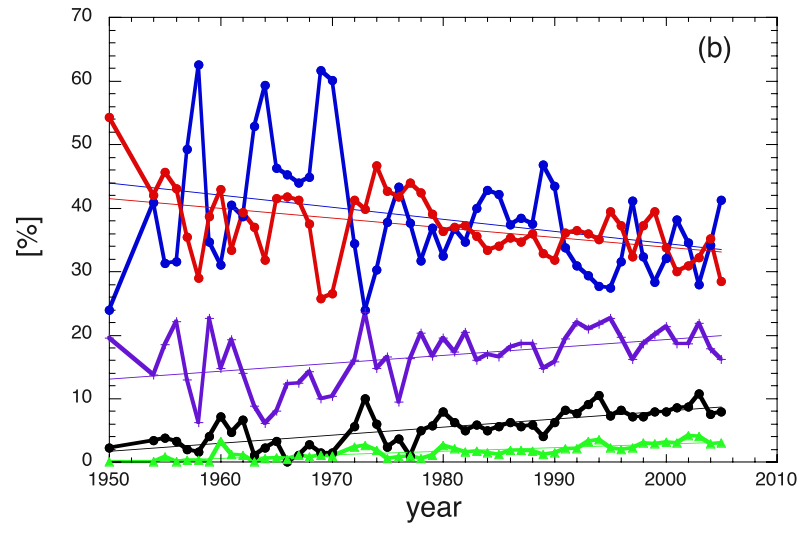

Figure 2. (a) Winter and (b) summer observations divided into drift speed categories expressed as percentages of the seasonal total: $0-5 \mathrm{~cm} / \mathrm{s}$ (blue), $5-10 \mathrm{~cm} / \mathrm{s}$ (red), $10-15 \mathrm{~cm} / \mathrm{s}$ (purple), $15-20 \mathrm{~cm} / \mathrm{s} \mathrm{(black),} \mathrm{and} 20-25 \mathrm{~cm} / \mathrm{s}$ (green). All trends are significant at the $95 \%$ level except that in the $5-10 \mathrm{~cm} / \mathrm{s}$ category during winter. 




b
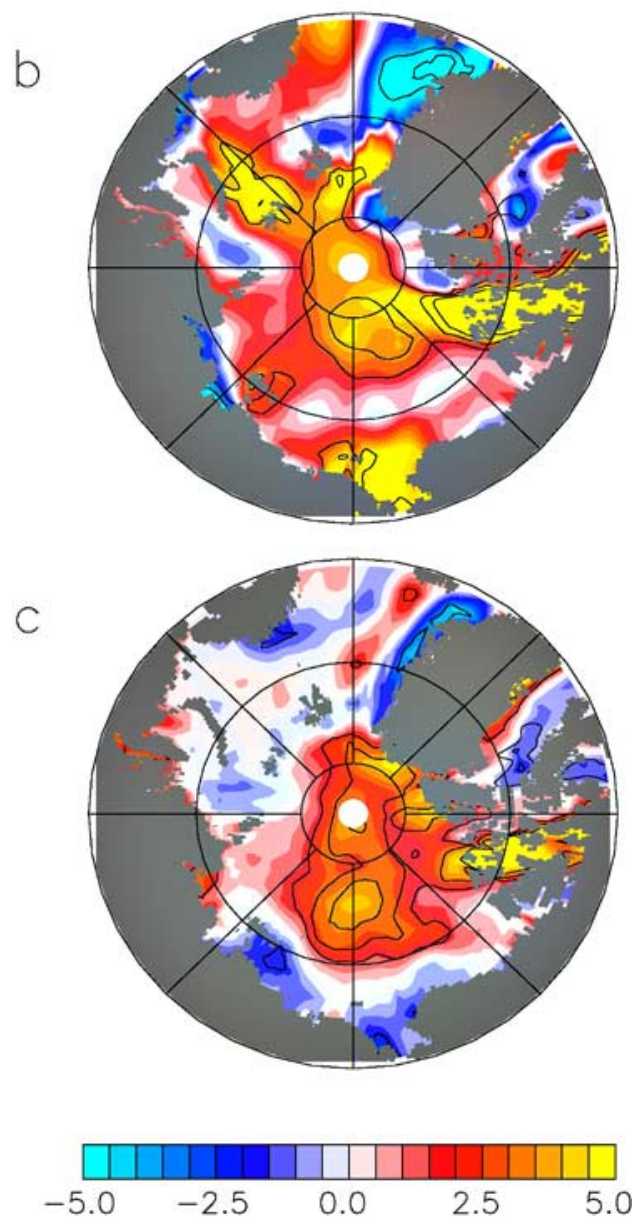

Figure 3. Trends of the NCAR/NCEP Reanalysis wind stresses for 1948-2006 for (a) annual, (b) winter, and (c) summer values. Black contours depict t-test values (with an interval of 1) greater than $2(95 \%$ and higher level of trend significance). Units are $1 . \mathrm{E}-4 \mathrm{~N} / \mathrm{m}^{2}$ per year.

drift speed increases (Figure 2). Only categories up to $25 \mathrm{~cm} / \mathrm{s}$ are shown. Each of the higher velocity categories constitutes less than $2 \%$ of the observations in any given year, whether summer or winter. The figures show the gradual shift of ice drift toward higher speeds. Here again the early 1990s period has a fleeting signal as a decreased percentage of buoys in the slowest drift category both in winter and summer data. The summer data show increased number of buoys in category $10-15 \mathrm{~cm} / \mathrm{s}$ in the early 1990s. In winter
(Figure 2a), all trends except for that in the $5-10 \mathrm{~cm} / \mathrm{s}$ category are significant, at a 95\% level. Percentages for 1954 (NP-03) and 1956 (NP-05) exhibit unusual deviations, but these fluctuations do not nullify the trend. The irregularities present in winter data are not seen in the summer drift data (Figure 2b) for which all trends shown, downward for speeds less than $10 \mathrm{~cm} / \mathrm{s}$, upward for speeds greater than $10 \mathrm{~cm} / \mathrm{s}$, are significant at a $95 \%$ level. The IABP only data (not shown) indicates that the drift speed categories greater than $10 \mathrm{~cm} / \mathrm{s}$ have significant upward trends during winter. For the summer months, significant trends (95\% or higher) are limited to categories with speeds above $15 \mathrm{~cm} / \mathrm{s}$ (all upward trends).

\section{Wind Stress Variability}

[10] An overwhelming portion of the driving force for sea ice drift is exerted by the atmosphere, with a much smaller portion coming from ocean mixed layer velocities, including tidal motion. Some of the kinetic energy from these sources is lost to internal sea ice friction. We analyze the wind stress from the NCEP/NCAR Reanalysis to test the increase in storm intensity/frequency; our analysis cannot separate the two effects but it emphasizes the change in the impact of atmospheric forcing on the sea ice. For our analysis, we compute the annual wind stress as an average of the magnitude of monthly stresses. We also separate the wind stress seasonally into summer wind stress averaged over May through October and winter wind stress averaged over November through April. The annual, winter, and summer trends in the magnitude of the NCEP/NCAR wind stress are shown in Figure 3 over the years 1948 to 2006. The strongest trend occurs over the TDS in all seasons, but the trends in the annual and summer values have higher significance (95\% or higher based on the t-test values) than the winter trend (due to enhanced storminess). This enhanced summer cyclone activity is in agreement with many of the analyses that are based on SLPs [McCabe et al., 2001; Zhang et al., 2004; Sorteberg and Walsh, 2008], while contrasting the results of Serreze and Barrett [2008]. The Arctic coastal trends are much weaker or nonexistent, again agreeing with Atkinson [2005], and are negative in the summer. In contrast to wind stress behavior in the TDS region, weakening wind stresses occur in two regions, the East Greenland Current and Baffin Bay. The downward trend over the western GIN Seas and Baffin Bay is significant at the $95 \%$ level.

\section{Discussion}

[11] In this study we highlighted long-term changes in sea ice drift speeds and their relationship to atmospheric forcing covering years 1950 to 2006 . We analyze ice drift data ranging from those taken at the early Russian North Pole Stations and during the International Geophysical Year ice camps to those collected by IABP buoys. Our results show a gradual acceleration in sea ice drift over the 50 years analyzed. The accelerating trend in the central Arctic is present both in winter and summer observations, with nearly equal statistical significance. Since the atmosphere is responsible for the main forcing of the sea ice, the obvious conclusion is that the increased sea ice speeds 

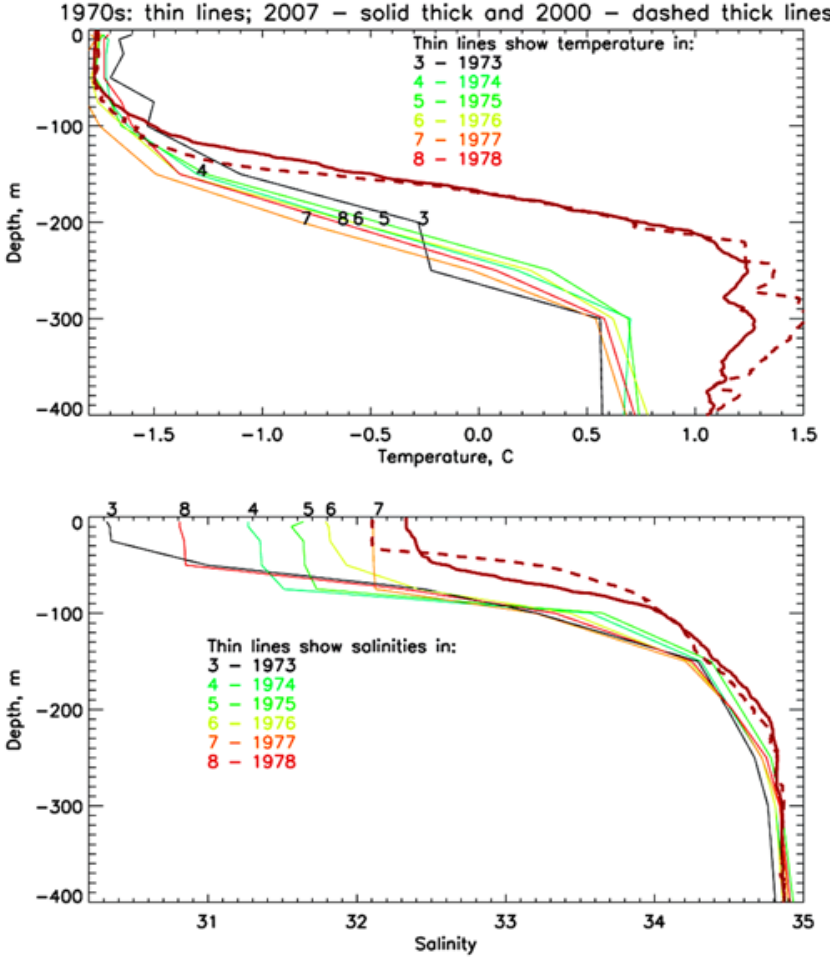

Figure 4. North Pole water temperature and salinity in 2000 (thick dashed red) and 2007 (from NPEO mooring; thick solid red) relative to temperatures in the 1970s, depicted as thin colored lines labeled 3 (1973), 4 (1974), etc.

relate to increased storm frequency and/or intensity. This has been suggested based on atmospheric analysis of storm tracks as compiled from SLPs by Serreze et al. [1997, 2000], McCabe et al. [2001], Zhang et al. [2004], and Sorteberg and Walsh [2008]. Analysis of sea ice drift from the central Arctic confirms an increasing trend in Arctic atmospheric storm activity lasting over 50 years, with its main impact concentrated in the TDS. The increased storm activity and sea ice drift does not necessarily lead to longterm increase in sea ice export from the Arctic. Indeed, Ron Kwok (personal communication) concludes that for the past 10 years, his updated ice area flux via Fram Strait (as observed from satellites) has "not been more remarkable than in the past." A more important effect on the Arctic Ocean upper ocean is likely to come from the increased turbulence imposed by increased ice drift speeds. The Arctic upper ocean is dominated by a relatively fresh 50 -meter water layer. Below the mixed layer, water salinity increases, forming a cold halocline (CHL) with temperatures near the freezing point. The CHL serves as a barrier between the fresh upper ocean waters and the warm and saline Atlantic waters. Several studies have noted the retreat of the CHL in the Nansen Basin in the early to mid 1990s [Steele and Boyd, 1998], but after that the CHL partially recovered according to Boyd et al. [2002] and Björk et al. [2002]. However, after this recovery, the mixed layer salinities were still above the relatively low water salinity level of the 1970s reflected in the Environmental Working Group (EWG) Atlas. Steele and Boyd [1998] and Boyd et al. [2002] speculate that the major cause of the observed CHL variability was changes in atmospheric circulation, sea ice drift, and surface currents resulting in an eastward redistribution of the main Siberian river waters and hence leaving behind an upper-layer freshwater deficit in the Nansen basin. This hypothesis is partially supported by several numerical modeling studies [e.g., Newton et al., 2008; Maslowski et al., 2000]. We argue that similar changes in the vertical ocean stratification can result from mixing processes due to increased storm activity the early 1990s (a period characterized by a strong cyclonic atmospheric circulation regime) and manifested in a local enhancement of ice drift speeds. Steele and Boyd [1998] noted also increased storminess as an additional cause of CHL retreat.

[12] Observations have established that Arctic mixed layer salinities in the recent decade exhibit their highest values since the 1950s as shown in EWG Atlas [Steele and Boyd, 1998; Boyd et al., 2002]. As an example, upper ocean changes at the North Pole are shown in Figure 4 which depicts temperature and salinity characteristics in the upper $400 \mathrm{~m}$ layer. The results from 2007 observations at the North Pole Environmental Observatory (NPEO) show that the CHL has shifted again toward the conditions of the mid 1990s and that the CHL salinity has increased not only relative to the 1970 s but also relative to the 2000 conditions reported by Boyd et al. [2002]. (The NPEO site is chosen because there are a large number of observations covering different decades/climate regimes.) Since this salinification is occurring with decreasing and thinning sea ice cover [Comiso, 2002, 2006], we speculate that the mixed layer salinification at NPEO is a consequence of the increased storm activity and associated halocline erosion. This is assuming that the salinity changes are not due to advection processes.

[13] Our analysis of sea ice drift supports the SLP results, indicating increased storm frequency and intensity for the past 50 years or so. While the last 50 years represent a warming climate, coupled model simulations of the $20^{\text {th }}$ century and $\mathrm{CO}_{2}$ scenario simulations do not agree with the changes in Arctic storm activity as inferred from ice drift or with the majority of the SLP analysis for the latter half of the $20^{\text {th }}$ century. This disagreement is critical to future climate change prediction regarding evolution of the Arctic ice-ocean system and its impacts, particularly maintenance of the halocline. We also speculate that the increased wind stirring of the ocean could hasten the transition of the Arctic Ocean toward weak stratification with the potential for deep convection that could provide a new sink for atmospheric $\mathrm{CO}_{2}$. Such a scenario would, of course, affect the whole climate system and its evolution.

[14] Acknowledgments. We are grateful for funding from the NASA Headquarters, NSF and IARC. Comments from two anonymous reviewers were very helpful in improving the manuscript. We thank Denise Worthen for help with graphics and Vicky Cullen for technical editing.

\section{References}

Atkinson, D. E. (2005), Observed storminess patterns and trends in the circum-Arctic coastal regime, Geo Mar. Lett., 25, 98-109.

Bengtsson, L., K. I. Hodges, and E. Roeckner (2006), Storm tracks and climate change, J. Clim., 19, 3518-3543.

Björk, G., J. Söderkvist, P. Winsor, A. Nikolopoulos, and M. Steele (2002), Return of the cold halocline layer to the Amundsen Basin of the Arctic Ocean: Implications for the sea ice mass balance, Geophys. Res. Lett., 29(11), 1513, doi:10.1029/2001GL014157. 
Boyd, T. J., M. Steele, R. D. Muench, and J. T. Gunn (2002), Partial recovery of the Arctic Ocean halocline, Geophys. Res. Lett., 29(14), 1657, doi:10.1029/2001GL014047.

Comiso, J. C. (2002), A rapidly declining perennial sea ice cover in the Arctic, Geophys. Res. Lett., 29(20), 1956, doi:10.1029/2002GL015650.

Comiso, J. C. (2006), Abrupt decline in the Arctic winter sea ice cover, Geophys. Res. Lett., 33, L18504, doi:10.1029/2006GL027341.

Gascard, J.-C., et al. (2008), Exploring Arctic transpolar drift during dramatic sea ice retreat, Eos Trans. AGU, 89(3), 21-22.

Koenig, W., R. Sausen, and F. Sielman (1993), Objective identification of cyclones in GCM simulations, J. Clim., 6, 2217-2231.

Manson, G. K., and S. M. Solomon (2007), Past and future forcing of Beaufort Sea coastal change, Atmos. Ocean, 45, 107-122.

Maslowski, W., B. Newton, P. Schlosser, A. Semtner, and D. Martinson (2000), Modeling recent climate variability in the Arctic Ocean, Geophys. Res. Lett., 27, 3743-3746, doi:10.1029/1999GL011227.

McCabe, G. J., M. P. Clark, and M. C. Serreze (2001), Trends in Northern Hemisphere surface cyclone frequency and intensity, J. Clim., 14, $2763-$ 2768.

Newton, R., P. Schlosser, D. G. Martinson, and W. Maslowski (2008), Freshwater distribution in the Arctic Ocean: Simulation with a high-resolution model and model-data comparison, J. Geophys. Res., 113, C05024, doi:10.1029/2007JC004111.

Nghiem, S. V., I. G. Rigor, D. K. Perovich, P. Clemente-Colon, J. W. Weatherly, and G. Neumann (2007), Rapid reduction of Arctic perennial sea ice, Geophys. Res. Lett., 34, L19504, doi:10.1029/2007GL031138.

Serreze, M. C., and A. P. Barrett (2008), The summer cyclone maximum over the central Arctic Ocean, J. Clim., 21, 1048-1065.
Serreze, M. C., F. Carsey, R. G. Barry, and J. C. Rogers (1997), Icelandic low cyclone activity: Climatological features, linkages with the NAO and relationships with recent changes in the Northern Hemisphere circulation, J. Clim., 10, 453-464.

Serreze, M. C., et al. (2000), Observational evidence of recent change in the northern high-latitude environment, Clim. Change, 46, 159-207.

Sorteberg, A., and J. E. Walsh (2008), Seasonal cyclone variability at $70 \mathrm{~N}$ and its impact on moisture transport into the Arctic, Tellus, Ser. A, 60, $570-586$.

Steele, M., and T. Boyd (1998), Retreat of the cold halocline layer in the Arctic Ocean, J. Geophys. Res., 103, 10,419-10,435.

Stroeve, J., M. M. Holland, W. Maier, T. Scambos, and M. Serreze (2007), Arctic sea ice decline: Faster than forecast, Geophys. Res. Lett., 34, L09501, doi:10.1029/2007GL029703.

Zhang, X., J. E. Walsh, J. Zhang, U. S. Bhatt, and M. Ikeda (2004), Climatology and interannual variability of Arctic cyclone activity: 1948-2002, J. Clim., 17, 2300-2317.

I. Ashik, Arctic and Antarctic Research Institute, St. Petersburg 199397, Russia.

S. Hakkinen, NASA Goddard Space Flight Center, Code 614.2, Greenbelt, MD 20771, USA. (sirpa.hakkinen@nasa.gov)

A. Proshutinsky, Woods Hole Oceanographic Institution, Woods Hole, MA 02543, USA. 